Original Research Paper

\title{
Study of the Parameters of Steam Assisted Gravity Drainage (SAGD) Method for Enhanced Oil Recovery in a Heavy Oil Fractured Carbonate Reservoir
}

\author{
Arzhang Nabilou \\ Center of Natural Resources and Environment (CERENA), \\ Instituto Superior Técnico, Technical University of Lisbon, Av. Rovisco Pais, 1049-001, Lisbon, Portugal
}

\author{
Article history \\ Received: 24-08-2016 \\ Revised: 03-09-2016 \\ Accepted: 06-09-2016
}

Email:arzhng.nabilou@tecnico.ulisboa.pt

\begin{abstract}
By increasing in the use of nonrenewable energy and decreasing in discovering hydrocarbonic reservoirs, in near future the world will encounter with a new challenge in the field of energy, so increase in recovery factor of the existing oil reservoirs is necessary after the primary production. In one hand the existence of untouched heavy oil reservoirs in Iran and lack of producing from them and maturity of light oil reservoirs to 2nd and 3rd stage of their production age in other hand make the development and production of these heavy oil reservoirs necessary in Iran. The goal of this study is to survey common methods of producing oil reservoirs and appliance in heavy oil reservoirs of Iran especially in Kuh-e-Mond. For choosing the best EOR method we should consider factors such as the reservoir fluid and rock characteristics, availability of injection material, available equipments and other items. One way to choose an optimized method is the comparison of reservoirs' parameters in successful EOR projects with the considered reservoir. However, it should be consider that each reservoir has its especial characteristics and we can not give certain idea about it. Thermal methods have the most useage in the recovery of the world's heavy oil and between these methods; steam injection with the most amount of oil production has terrific importance. The gained results show that the best way for recovery heavy oil of Sarvak reservoir of Kuh-e-Mond is thermal way and especially steam injection Steam modeling by activating gravity drainage drive process by using steam injection (SAGD) which is designed in a reservoir model in Sarvak reservoir of Kuh-e-Mond has been successful.
\end{abstract}

Keywords: SAGD, Heavy Oil Reservoir, EOR, Kuh-e-Mond, SARVAK

\section{Introduction}

The known amounts of heavy oil reserves are 3,396 billion barrels of initial oil in place, including 30 billion barrels as futuristic additional oil. The whole discovered bitumen reserves are about 5,505 billion barrels of initial oil in place, including 993 billion barrels as futuristic additional oil (USGS, 2007). Venezuela and North-America especially Canada have the greatest accumulation amounts of bitumen and heavy oil reserves in their carbonate and sandstone reservoirs (Nasr and Ayodele, 2006). Iran has the world's second largest reserves of conventional crude oil of 133 MMMSTB. Therefore, it is necessary to undertake extensive study to find suitable enhanced oil recovery methods to maximize the recovery of such these large amounts of reserves (Abbasi et al., 2015). There are different methods for producing from unconventional reservoirs based on the principle of lowering bitumen and heavy oil intrinsic viscosity. This reduction may be performed using injection of steam inside the reservoir (increasing the temperature of reservoir contents) or by dissolution of special solvents into the bitumen (solvent injection) or by use of benefits of both of them. Hot water injection, in-situ combustion, Steam-Assisted Gravity Drainage (SAGD) and Cyclic Steam Stimulation (CSS) are examples of thermal processes and vapor extraction (VAPEX) (Butler and Mokrys, 1991) is an example of solvent injection method. Among the thermal processes, SAGD is the most efficient and promising method which was pioneered and developed by (Butler and Mcnab, 1981). 
This method benefits from advantage of horizontal well technology which has a greater contact area to the reservoir. In this method two horizontal wells are drilled with vertical spacing about $5 \mathrm{~m}$ at the point with greatest height from the top of the reservoir to have a greater recovery. The bottom well is considered as producer while the upper one is injector. Heat will be transferred into the reservoir by injection of steam via injector. The formation and its contents will be heated up to the steam temperature gradually due to the high heat capacity of steam. Bitumen viscosity decreases by increasing temperature within the steam contacted area and forms a reverse triangle zone which is known as steam chamber area. This aforementioned region advances upward to reach to the top of the reservoir and then to the surrounding area (Butler, 1991). Gravity drainage is the principal mechanism of recovery process that helps to recover melted, mobile bitumen together with the amounts of steam which are condensed due to contact with cold oil at the boundary of steam chamber via horizontal production well. The amount of required steam is measured based on cold water equivalents to recover each unit of produced bitumen. The economic range of CSOR in the field condition is in the range of $2-10 \mathrm{~m} 3 / \mathrm{m} 3$ (Gates and Chakrabarty, 2006). SAGD recovery method has been tested by several experimental works and afterwards it has been implemented in some pilot cases. Here, numerical simulation on SAGD process in field conditions has been performed to peruse the effect of different parameters. The results were compared based on the recovery factor.

\section{Experimental Work}

\section{Geological Setting of the Studied Heavy Oil Field}

Kuh-e-Mond is the largest on shore Heavy Oil (HO) field in Iran, found in a giant anticline with a NW-SE trend, parallel to the Zagros orogenic belt (Fig. 1). Kuhe-Mond was discovered in 1931 and systematic exploration began in 1984. This relatively symmetrical anticline is $90 \mathrm{~km}$ long and $16 \mathrm{~km}$ wide with an estimated minimum $\mathrm{HO}$ resource base of $6 \mathrm{Bb}$ OOIP, found in three separate reservoirs with depths ranging from 400-1200 meters and oil viscosities of 570-1160 cSt in situ. A large number of faults cut the axial plane of the structure causing some strata displacements around the central and plunging parts of the structure. The average dip of the southwest and northeast flanks of the anticline is 17 and $15^{\circ}$, respectively (Moshtaghian et al., 1988; Shafiei et al., 2007).

\section{Reservoir and Fluid Properties at the Kuh-e-Mond}

A representative screening parameter database is vital in production technology screening and recoverable reserves evaluation of a family of $\mathrm{HO}$ reservoirs to decide which are the best reservoirs deserving of most attention. As the first part of a production technology selection program, rock and fluid properties for the $\mathrm{HO}$ reservoirs at the Kuh-e-Mond HO field in SW Iran were collected, reviewed and are summarized in Table 1.

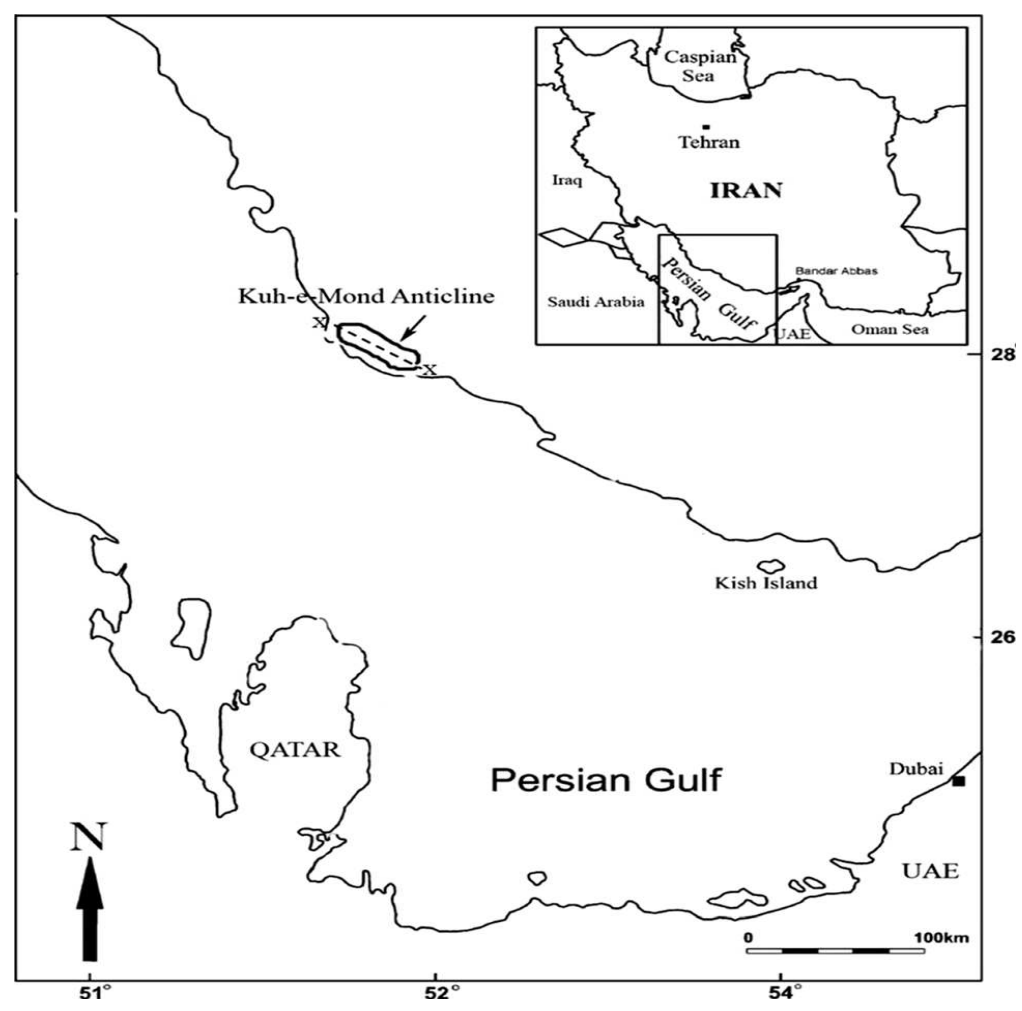

Fig. 1. Location of studied heavy oil reservoir 


\begin{tabular}{ll} 
Table 1. Properties of the reservoir rock and fluid & \\
\hline The reservoir primary pressure (psi) & 1400 \\
Primary temperature $\left(\mathrm{F}^{\circ}\right)$ & 150 \\
Water primary saturation degree (\%) & 22 \\
Oil primary saturation degree (\%) & 78 \\
Porosity (\%) & 13 \\
Kh fracture (md) & 200 \\
Kh matrix (md) & 50 \\
\hline
\end{tabular}

Table 2. The reservoir dimensions

\begin{tabular}{ll}
\hline The block number & 2250 \\
\hline Dimension in y axis & $900(\mathrm{Ft})$ \\
Dimension in $\mathrm{x}$ axis & $600(\mathrm{Ft})$ \\
Dimension in $\mathrm{z}$ axis & $300(\mathrm{Ft})$ \\
\hline
\end{tabular}

\section{Research Method}

Simulation is done for reservoirs with steam injection by SAGD method and by considering natural fractures and dual permeability system and model selection of the characteristics of networking system and blocks dimensions in three points of coordinate axis.

In this study, the characteristics of the reservoir rock such as the fractures distance from each other, fractues and matrix porosity, fractues and matrix permeability in three dimensions, matrix and fractures thermal characteristics such as heat conduction of rock, reservoir fluid characteristics involves the water in the fractures and their heavy oil and gas and their compressibility, thermal reduction of the reservoir top and bottom rocks and fluid characteristics (water and oil with no solvent gas), heavy oil and water molecular weight and their compressibility and oil thermal expansion, critical temperature and pressure of water and oil viscosity value at temperature and relative permeability values of oilwater and the reservoir primary conditions as crack and matrix saturation and crack and matrix temperature and producing information involves data related to injection and production well as the pressure of the bottom of the well in the beginning and its maximum for injection well and its minimum for production well and the value of injective steam are the factors which have been considered and during different scenarios of steam injection and its economic optimizing condition, have been surveyed.

\section{Model Description}

In this simulation STARS software is used which is from CMG Company; this software has the ability to do simulation for heavy oil production from fractured reservoirs with SAGD method.

The model network is considered Cartizen with 2250 blocks ( 15 block in the $\mathrm{x}$ axis, 10 block in $\mathrm{y}$ axis and 15 block in $\mathrm{z}$ axis), the properties of the designed model is shown in Table 2.

\section{Running the Simulation}

This simulation is done by considering two wells, one injection well and the other production well. After the model implementation for economic optimizing of the process, a desirable result has been gained about the injective steam properties, its rate, the distance between the wells and the wells position, the most effective factor in this process is the rate of injection fluid.

\section{The Survey of Parameters Sensitivity Analysis}

The injection Rate as the most important factor for oil production and other factors were surveyed in this experiment and following results have been gained.

\section{Optimize Injection Rate}

The considered time for this study is 10 years. In Fig. 5-10 the oil recovery rate is shown for different Rate of injection. This graph shows that the most range of oil production is related to injection fluid Rate equal to 35 barrels per day and the least is related to Rate equal to 5, but from Rate with more than 20 barrels per day, the difference in oil recovery is very low and it can be concluded that 20 barrels per day is optimized for the range of steam injection Rate.

In Fig. 2 the recovery range after one year is specified. As it is shown, in short time interval from injection beginning, recovery has not so difference in different Rate which is for high oil viscosity and then low gravity drive because oil was not warm in primary times. Then by reservoir warming and viscosity reduction, the role of gravity drive force and also the production increased. For getting better results and fast reaching to oil recovery, it is necessary to heat the neighbor environments of well and oil viscosity reduction to the extent that activates gravity drive.

The researches show that steam alternative injection will be very effective before applying of SAGD process in order to fast reach to oil production in the beginning of the project.

In Fig. 4 the range of oil production with different injection Rate is shown. As it is specified as the graph related to recovery, here the most rate of oil production is for Rate with 35 barrels per day but its difference with Rate with 20 barrels per day is low.

In Fig. 5 the range of produced oil in each injective Rate is specified to total water cut. As it is clarify in this graph, the range of water cut is constant till Rate equal to 15 , but more than this rate has great increase in Rate of water cut range, that we can conclude that here Rate equal to 15 is optimized. In Fig. 6 the cost is drawn at different Rates. It can be concluded from this graph that injective Rate to 20 barrels per day, the cost of produced oil is not so increased by lower Rate, but more than 20 , the injection cost has significant increase, so it is concluded from this graph that Rate equal to 20 is optimized. 


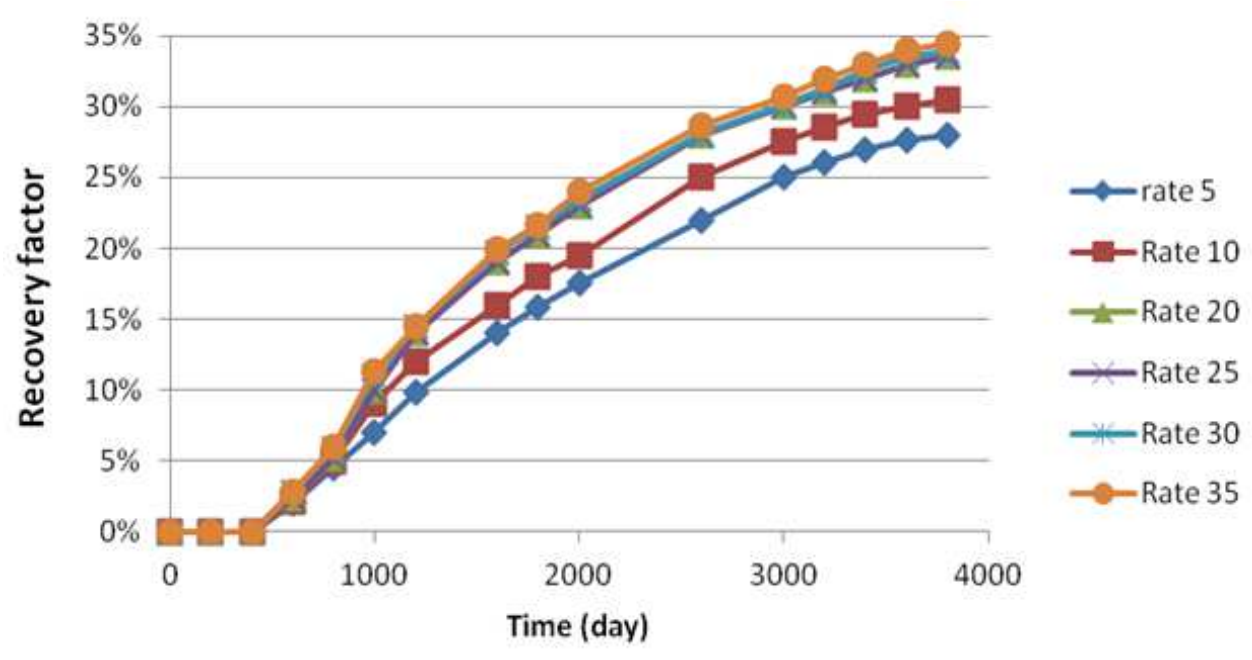

Fig. 2. Oil recovery rate in 10 years

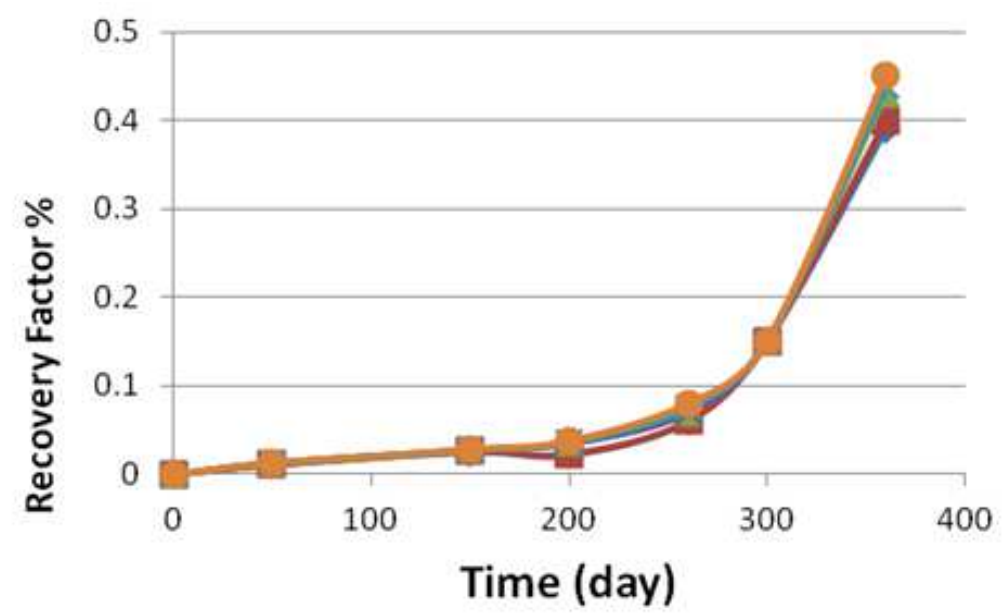

$\multimap$ rate 5

- -Rate 10

—-Rate 20

$\longrightarrow$ Rate 25

Rate 30

$\multimap-$ Rate 35

Fig. 3. Oil recovery rate in 1 year

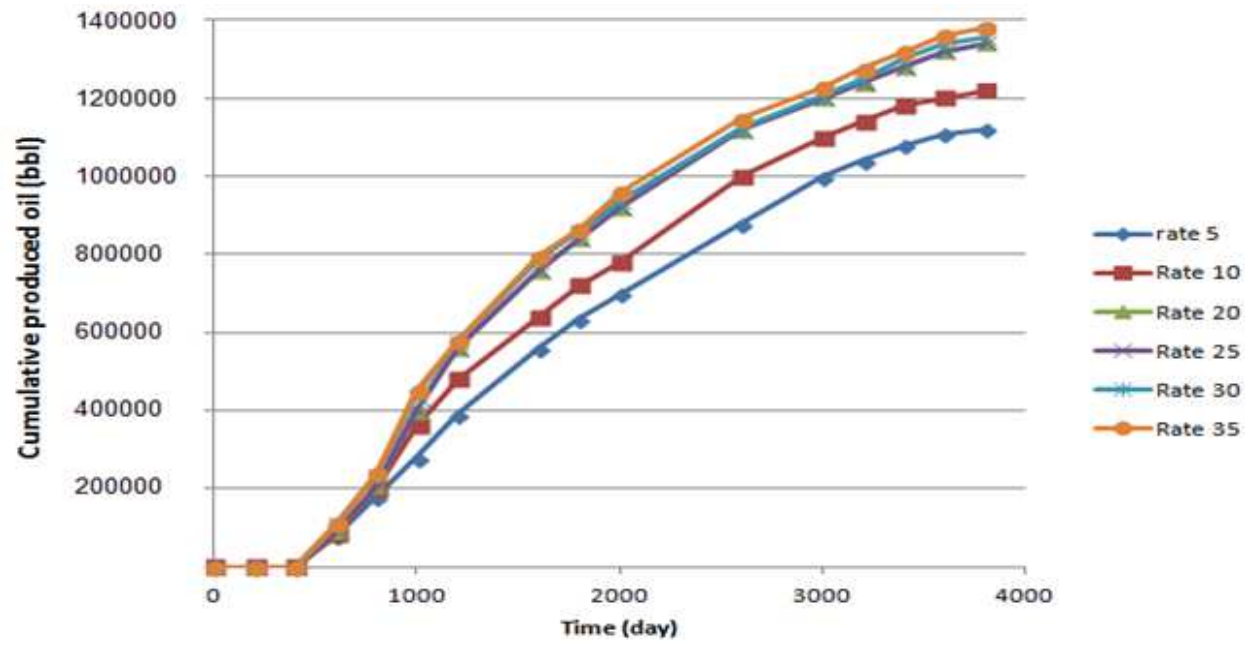

Fig. 4. The total rate of produced oil in 10 years at different injection Rate 


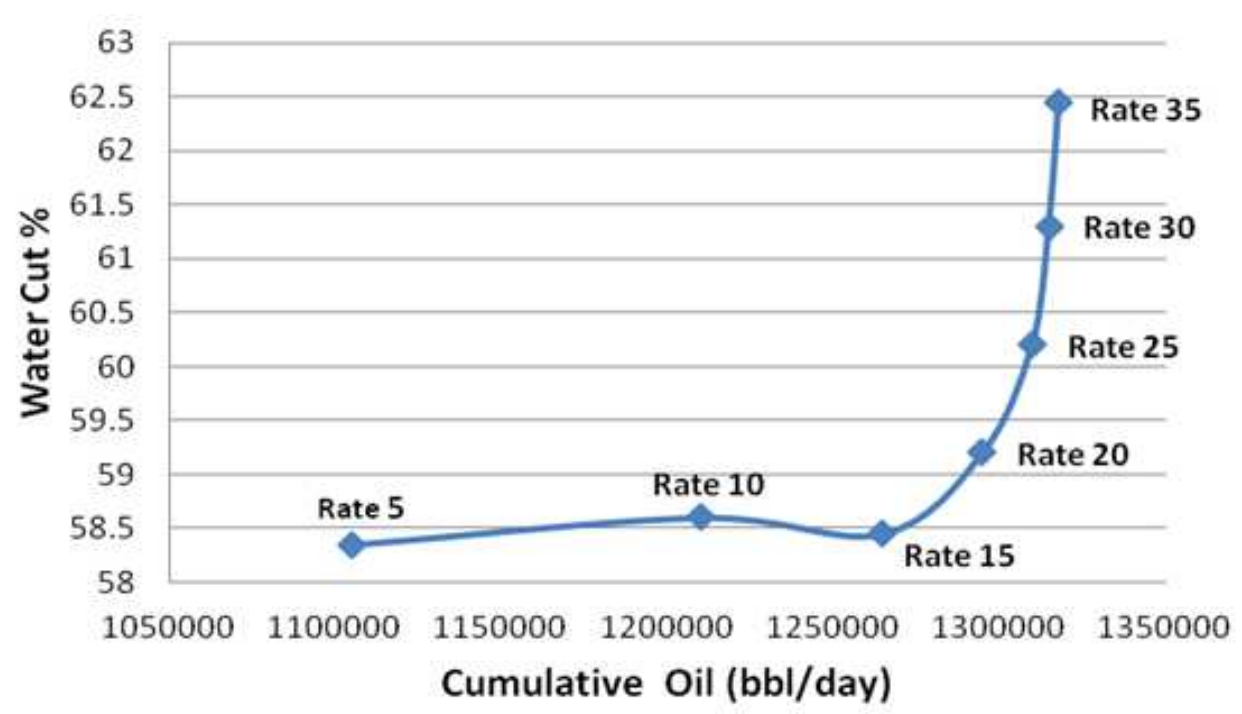

Fig. 5. Total range of produced oil in ten years at water cut

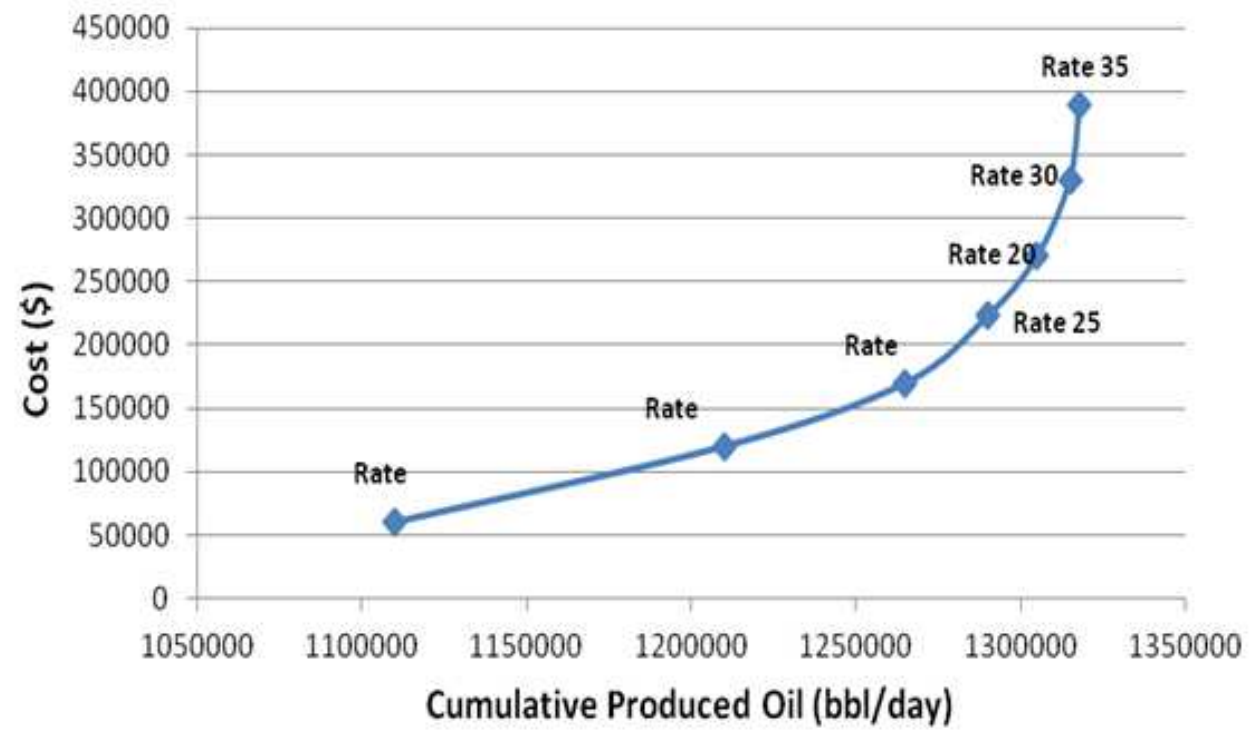

Fig. 6. The cost range at total produced oil in each injection Rate

Table 3. The steam cost for different injection Rate

\begin{tabular}{llll}
\hline $\begin{array}{l}\text { Injection } \\
\text { cost (Dollar) }\end{array}$ & $\begin{array}{l}\text { The range of produced } \\
\text { oil in } 10 \text { years }(\mathrm{bbl})\end{array}$ & $\begin{array}{l}\text { Total injection } \\
\text { in } 10 \text { years }(\mathrm{bbl})\end{array}$ & $\begin{array}{l}\text { Steam injection } \\
\text { Rate }(\mathrm{bbl} / \text { day) }\end{array}$ \\
\hline 54750 & 1105700 & 18250 & 5 \\
109500 & 1208900 & 36500 & 10 \\
164250 & 1265300 & 54750 & 15 \\
219000 & 1291300 & 73000 & 20 \\
273750 & 1305000 & 91250 & 25 \\
328500 & 1313700 & 109500 & 30 \\
383250 & 1317500 & 127750 & 35 \\
\hline
\end{tabular}

As it was observed in Table 3 the total rate of produced oil and also steam injection cost is calculated at each injection Rate, 3 American Dollar for each barrel and it is shown in graph 6 . Also in Fig. 7 the range of relative cost increase of each Rate to the lower rate is calculated and shown that like Fig. 6 that 20 barrels per day is optimized. 


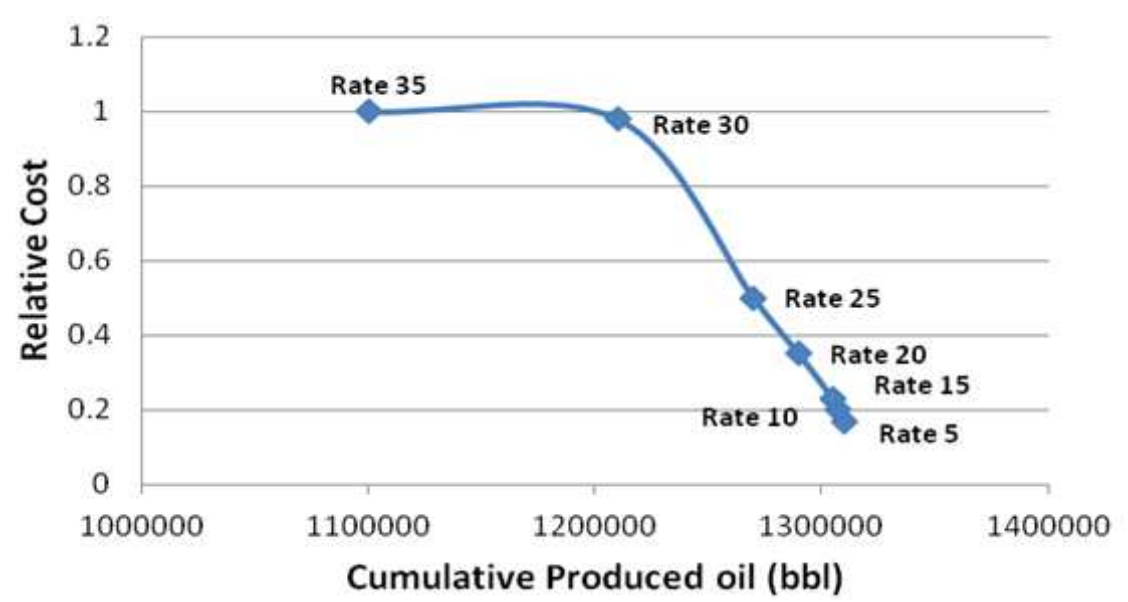

Fig. 7. Economic analysis of total range of produced oil in relation with cost increase toward injection Rate increase

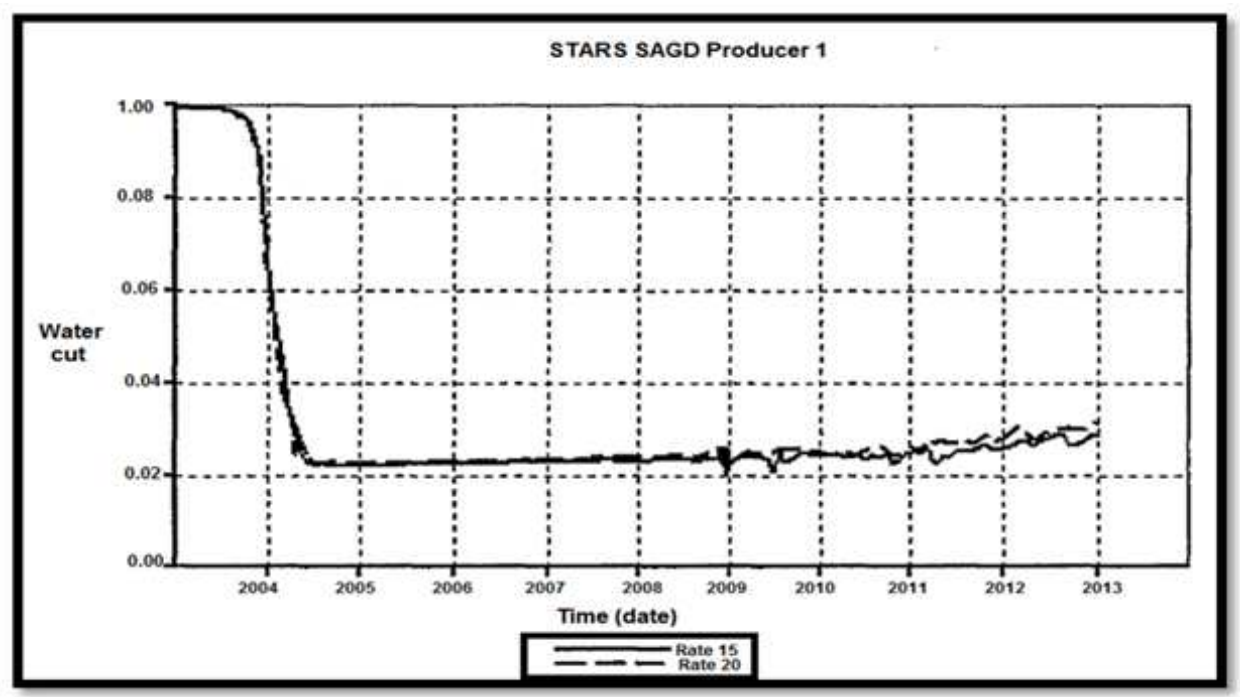

Fig. 8. The comparison of water cut between Rate 15 and 20 barrels per day

By attending to this point that the results of Rate 15 and 20 are similar, the range of water cut of these two rates is shown at time, but as it is observed in Fig. 8, the results are very similar.

Totally, it is concluded from the graphs that our production rate is optimized between 15 and 20 based on injection Rate and it is economically profitable.

\section{Surveying the Distance between Injection and Production Wells (Vertical)}

One of the parameters which has effective role in oil production in above mentioned method, is the distance between injection and production wells (Gates and Chakrabarty, 2006). Because it effects in heat wasting through reservoir bottom rocks and water production value because of fingering. So in the discussed model we change the distance between production and injection wells in three statuses:
- Injection well be three blocks upper than production well

- Injection well be six blocks upper than production well

- Injection well be nine blocks upper than production well

And the results are as follows:

In Fig. 9, the difference is observable in three statuses. It means that their recovery factor is different so the distance between the wells has role in cumulative recovery factor. The difference is very low in statuses (B) and $(\mathrm{C})$ and in $(\mathrm{A})$ status, the minimum recovery factor is gained. Because in this status since production well is located three blocks lower than injection well, so an amount of steam heat is rather transformed to bottom rocks and it is wasted. So the range of oil viscosity and its gravity drive is low and then recovery factor is minimized. 


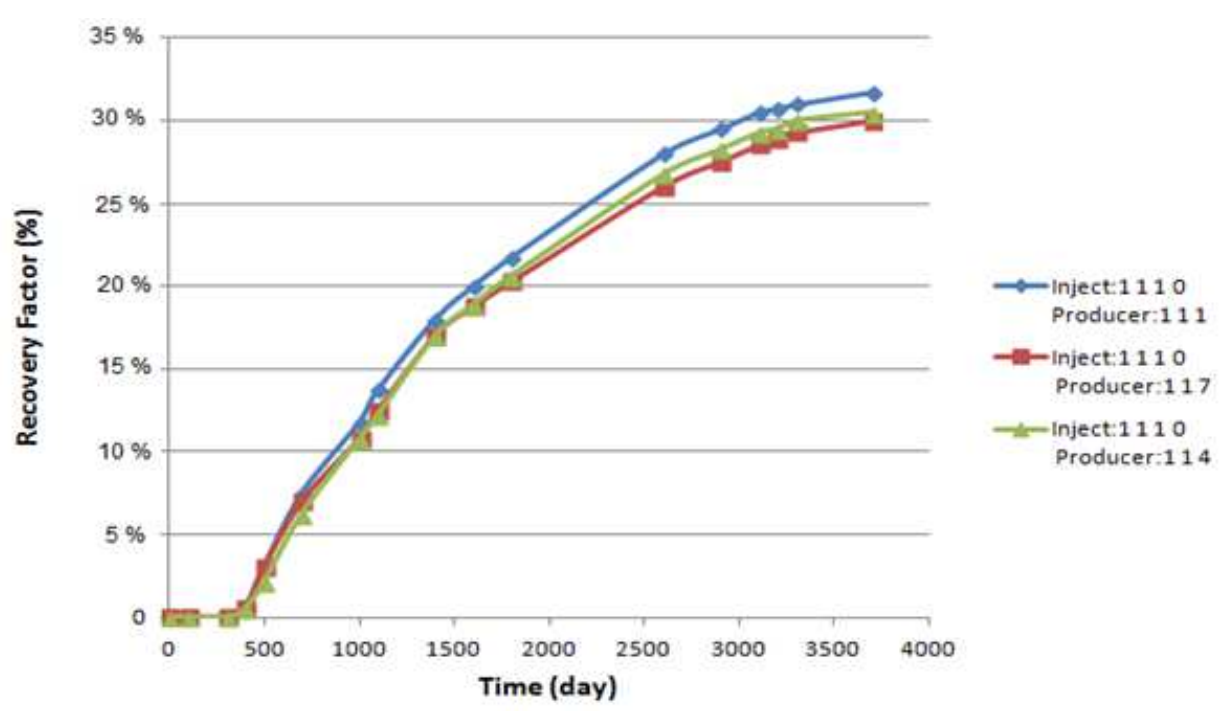

Fig. 9. The range of oil recovery by considering vertical distance of production and injection wells

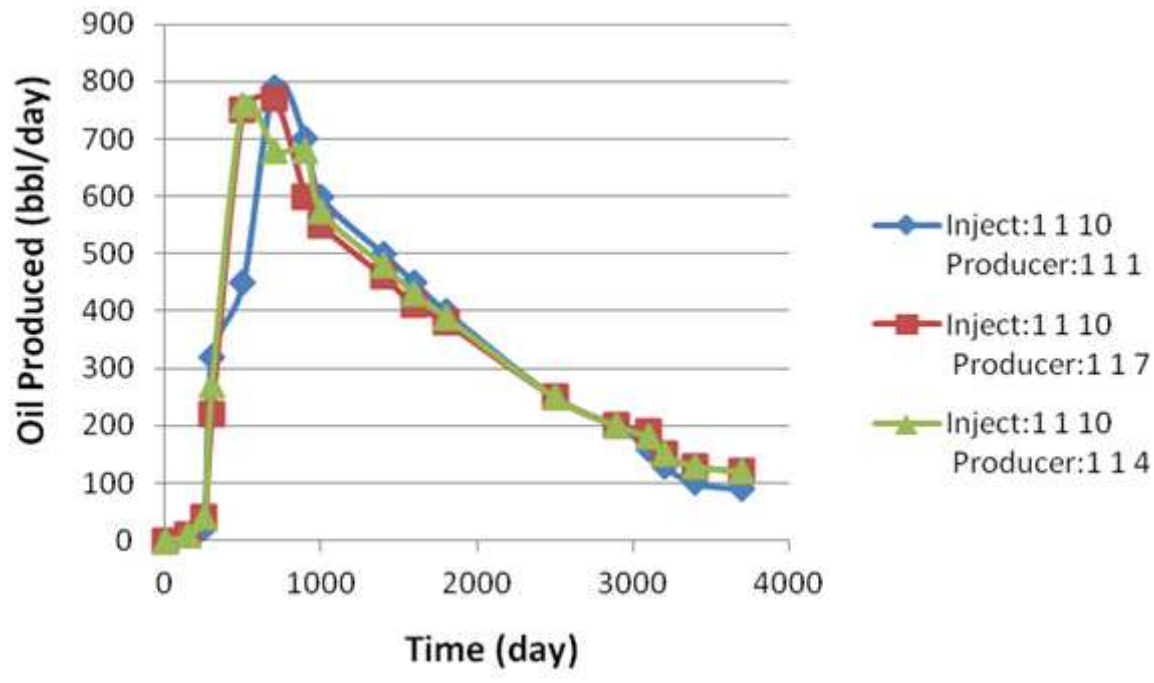

Fig. 10. The range of daily oil production by considering vertical distance of production and injection wells

In Fig. 10 produced oil rate has different values for the three statuses and oil Rate is minimized in (A) status and the reason was said in previous part. So it is concluded that the wells' distance are to some extent effective in produced oil Rate.

In Fig. 11 as it is seen, there is low difference between the three statuses and (A) status has the least value which was described in previous part, So well distance is effective to some extent in oil production value.

In Fig. 12, the range of produced water is similar for three statuses, so the wells distance has little effect on the water production.

By attending to the issues of this part it can be concluded that (C) status, that is production well be in the bottom and injection well be 9 blocks upper than it, is the best status for well locating. Because recovery factor and Rate and the oil production deal is more than the two other statuses and the range of produced water is lower than the two other statuses.

Typically $5 \mathrm{~m}$ vertical spacingis considered between the horizontal injection wells and the horizontal production well in the field conditions.

\section{The Survey of Matrix Porosity}

The rate of matrix porosity is one of the important parameter in oil production with above mentioned method, because it states the range of pore volume and oil in situ. So it has an important role in production oil rate (Souraki et al., 2012). So in discussed model, the matrix porosity has been surveyed for $0.1,0.13$ and 0.15 values and the results are as follows. 


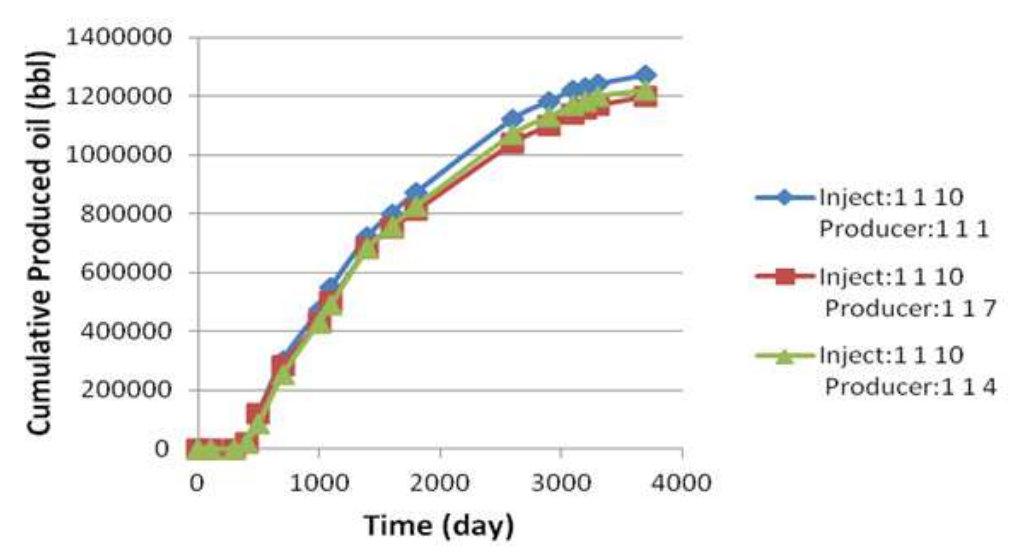

Fig. 11. The total range of produced oil by considering vertical distance of production and injection wells

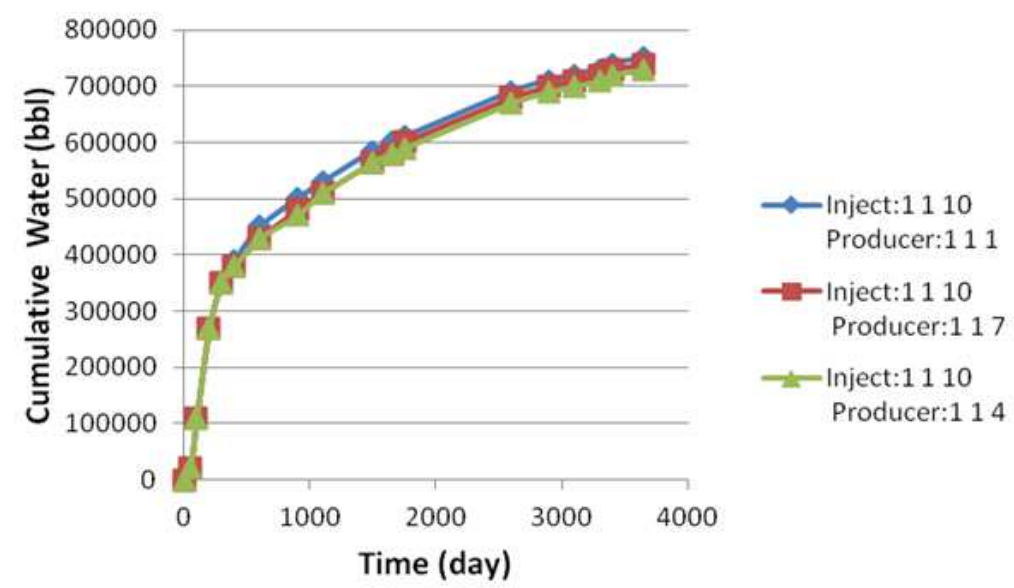

Fig. 12. The total range of produced water by considering vertical distance of production and injection wells

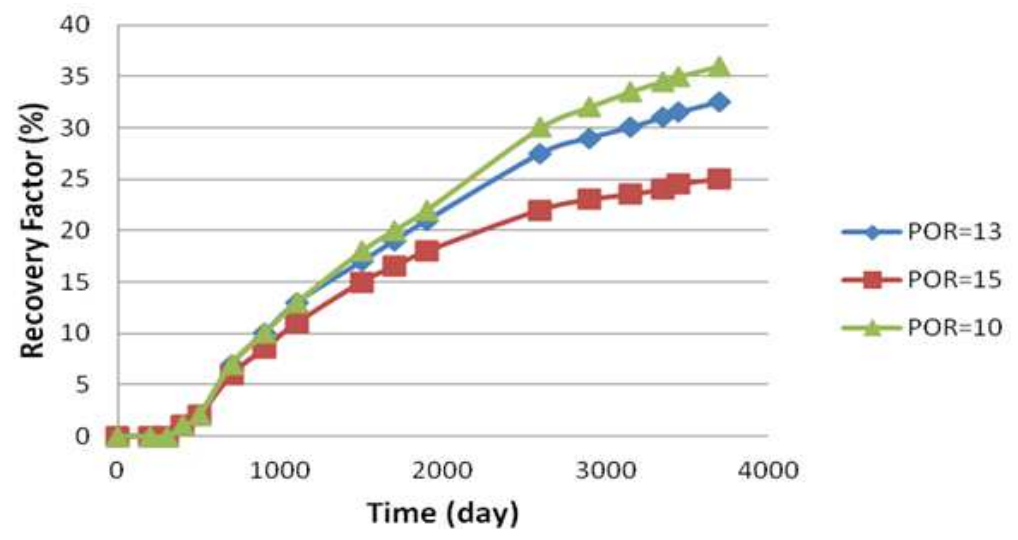

Fig. 13. The range of oil recovery at porosity changes

In Fig. 13 as it is seen, there is a significant difference for recovery factor between different statuses of matrix porosity. The lowest recovery factor value is seen for porosity 0.15 and the highest value is seen for porosity 0.1 . Because by decrease in porosity, the pore volume will be lower and the value of oil in situ will be lower too and the amount of steam for oil mass units (it is constant for injective steam Rate) increases rather than the status in which the porosity is more and there is more oil, so it will be hotter and its viscosity is more, oil will fall and flow toward the well and will be produced.

In Fig. 14 it is seen that the range of oil produced Rate is different for different statuses of porosity, which is minimized for porosity 0.1 and maximized for porosity 0.15 . So porosity is to some extent effective in produced oil Rate. 


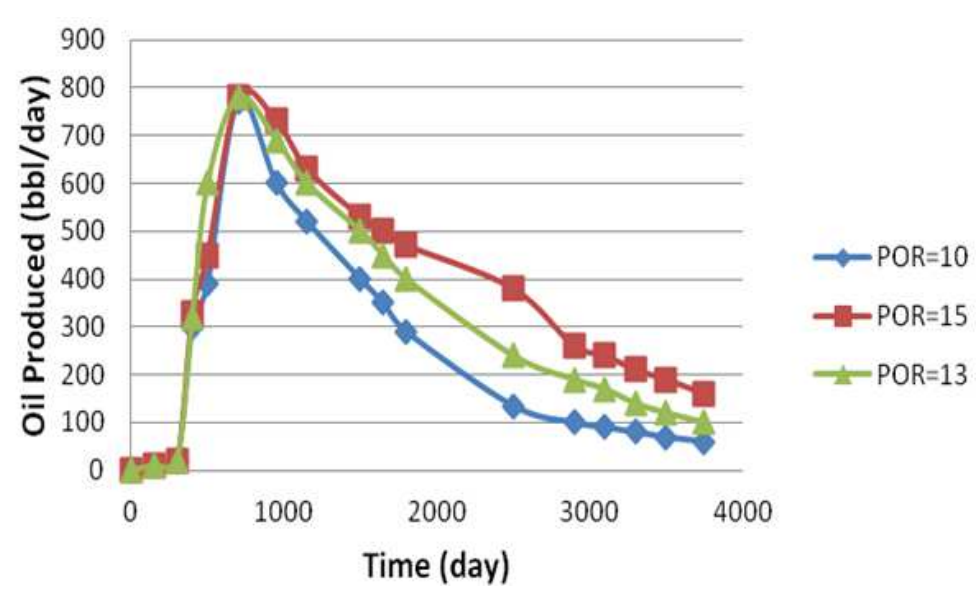

Fig. 14. The range of daily oil production at porosity changes

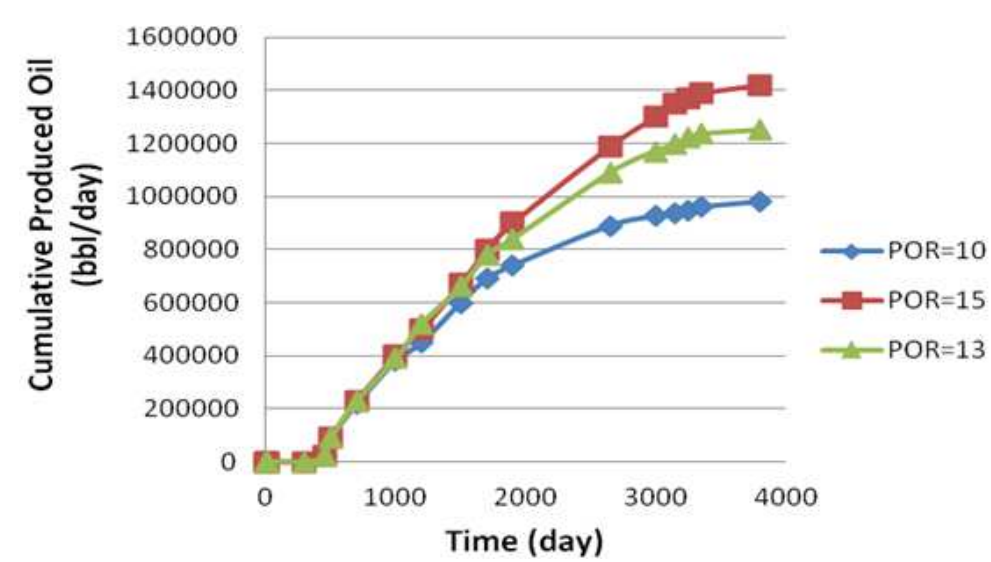

Fig. 15. The total range of produced oil at porosity differences

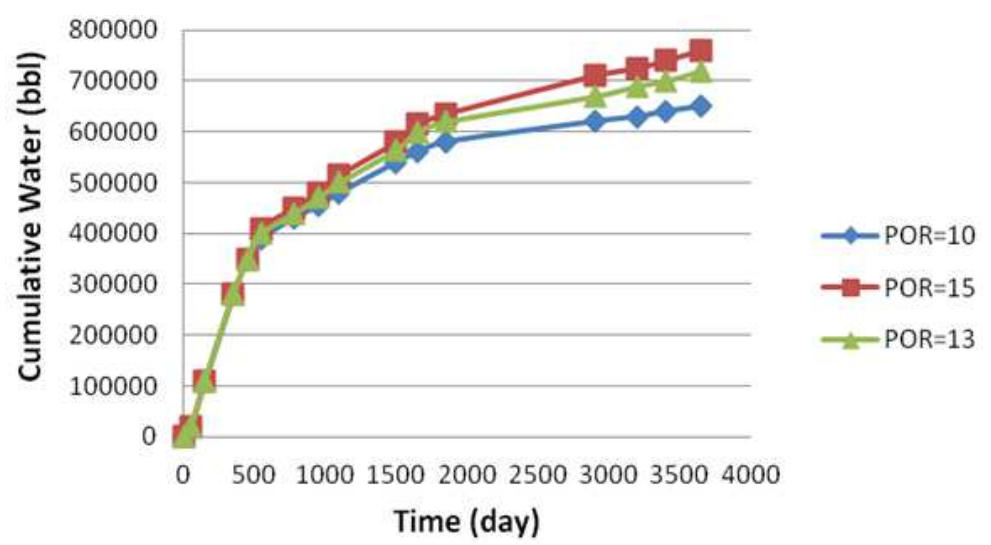

Fig. 16. The total range of produced water at different porosity

In Fig. 15 it is observed that the values of produced oil is different for different statuses, which is minimized for porosity 0.1 and maximized for porosity 0.15 and its reason was mentioned in the beginning.

In Fig. 16 it is observed that the differentiation in different statuses is observable for produced water cumulative. Because the pore space is more in high porosity and in fix primary saturation of water for this status, there is more water value than in low porosity and when because of oil heating, upper blocks fall to downer blocks, in one moment, the bottom matrix block is completely saturated by oil and the water of block exists from the block to (SWC) extent (residual water saturation) which results in more water production in high porosity status. So porosity is effective on the value of produced water. 


\section{The Survey of Matrix Permeability}

The range of matrix permeability is the most important factor in oil production method, because in gravity drainage, the hot oil in the matrix has an effective role.when oil temperature increase, the range of oil gravity drainage speed increases (Souraki et al., 2013). The discussed model permeability value changes such as 5, 35 and 100 millidarcy $(m D)$ and the results are shown as follows.

In Fig. 17 the difference of recovery factor is low for all of the statuses and for 100 millidarcy $(m D)$, it is maximized and for $5 \mathrm{mD}$ is minimized, because as it was mentioned by increase in permeability, passing and flowing of oil and gravity drainage of hot oil will be more and faster so the value of cumulative recovery factor related to $100 \mathrm{mD}$ will be maximized.

In Fig. 18 it is seen that the difference between oil production rate is very low. So permeability in this confine of changes has no effect on produced oil. However it is more for $100 \mathrm{mD}$ and it is maximized.

In Fig. 19 it is observed that there is no significant change in different status to total produced oil.

In Fig. 20 it is seen that the produced water rate in different statuses has no difference.

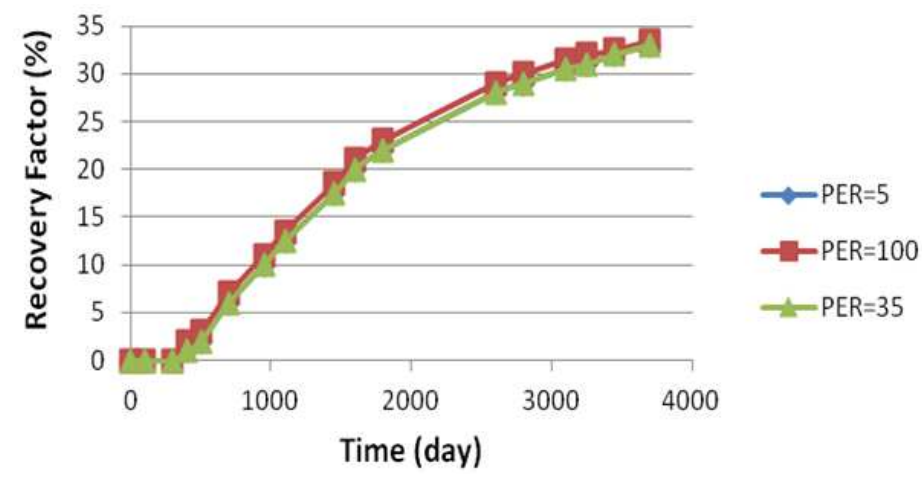

Fig. 17. The rate of oil recovery at permeability changes

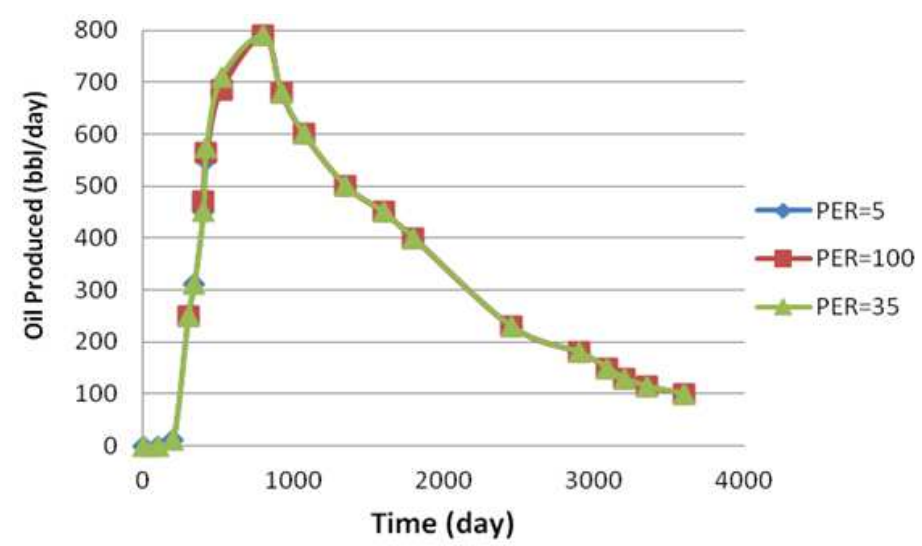

Fig. 18. The rate of daily oil production at permeability changes

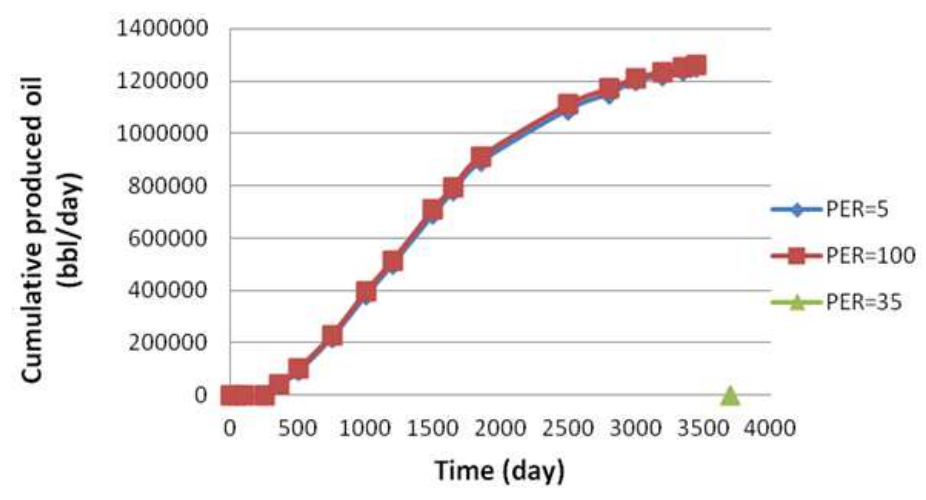

Fig. 19. The total range of oil production at permeability changes 


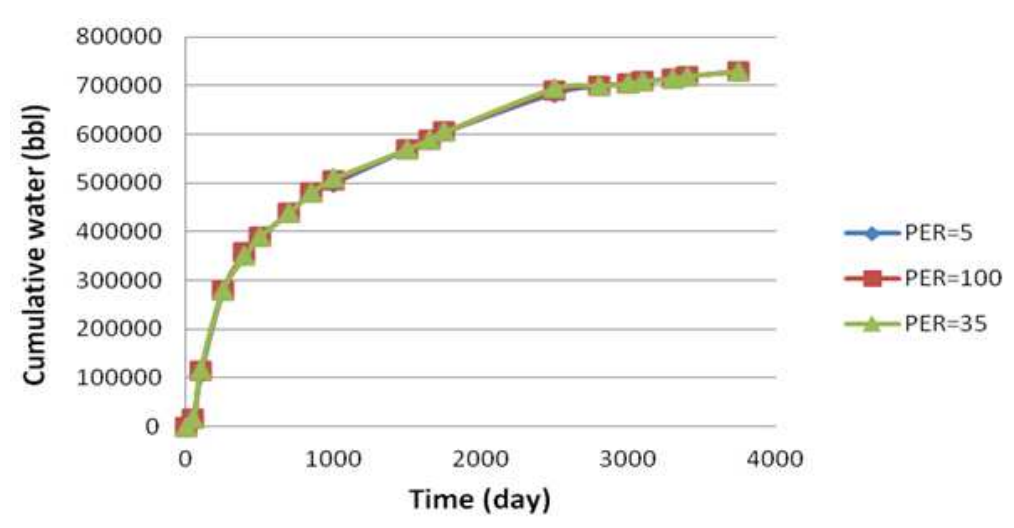

Fig. 20. The total range of water production at permeability changes

\section{Results and Discussion}

In this research paper we studied several paramaeters that effect SAGD method result on Recovery factor.

In Fig. 1-6 we can see that the besr rate of Injection is 15-20 barrel per day and this amount is economically reasonable, has the best oil to water ratio. Second parameter is the vertical distance of injection and production wells, By attending to the issues of this part it can be concluded that (C) status, that is production well be in the bottom and injection well be 9 blocks upper than it, is the best status for well locating. Because recovery factor and Rate and the oil production deal is more than the two other statuses and the range of produced water is lower than the two other statuses. Third parameter is Porosity, It is shown in Fig. 13-16, porosity is effective on the value of produced oil and water. In general, reservoirs with higher porosity have better quality for SAGD process considering commercial and economic issues. Forth parameter permeability, is also effective on total produced oil but in this confine of the matrix permeability has no effect on total produced water.

\section{Conclusion}

- Producing heavy oil reservoirs can have proper recovery based on engineering principles

- By considering the reduction of new resources of hydrocarbon, increase of recovery from the primary reservoir is necessary after the primary production. Also the existence of heavy oil reservoirs in Iran and lack of producing from them makes necessary to produce these reservoirs

- In selection of the best production methods from heavy oil reservoirs, some factors are considered as reservoir fluid and rock as screening of the recovery parameters can be very useful in this action

- The most effective methods to increase recovery from heavy oil reservoirs are thermal methods. In selection of the best method for heavy oil recovery is the use of technical knowledge and the performed researches in the advanced countries of the world such as Canada, is very useful

- Sarvak reservoir of $\mathrm{M}$ field is from carbonate and fractured type and by attending to this point that most of the world reservoirs are from sandrstone, in relation to this reservoir (fracture carbonate reservoir involving heavy oil), basic researches should be done

- By considering the recovery parameters screening and the results of simulation the best options for the heavy oil of Sarvak reservoir of $M$ field is steam injection methods, such as VAPEX, WASP, SAGD and EA-SAGD and immiscible gas injection

- The simulation which was done on the Sarvak reservoir of Kuh-e-Mond field just involve a part of the reservoir as an indicator (sector model) and is distributable for that part quantitative and for this part qualitative

- In the study of the performed simulation, the rate of injective Rate is experimented as the most important controllable factor of oil recovery and by surveying of different injective Rate it was resulted that for the designed Rate model, the optimized injective steam is between 15 and 20 barrels per day (equal to water)

- By using newer software in the future and identification of total reservoir information and designing the reservoir real model, the real result will be gained

\section{Recommendations}

By attending to this point that the properties of heavy oil reservoir of Iran involves the significant confine of the reservoir fluid and rock under different physical conditions of temperature and pressure in order to reach a general conclusion about enhanced oil recovery of Iran reservoirs and also quantitative results about Sarvak reservoir of $\mathrm{M}$ field, it is recommended that the following titles be studied and considered: 
- The study of M field reservoir simulation as sector model and consideration of other variables of the reservoir and increase of considered changing scope in this study $\left(\mathrm{P}_{\mathrm{C}}, \mathrm{K}_{\mathrm{C}}, \mathrm{K}, \mathrm{P}, \ldots\right)$

- The general study of Sarvak reservoir (a full field study) to specify the gained qualitative results in a quantitative form under different production scenarios to make a better selection for recovery

- The repetition of the study method of $\mathrm{M}$ field for other heavy oil reservoirs as simulation study (sector model) and then the reservoir general study

- The study about using gas injection process to horizontal wells and the path for locating the injection and production wells together, to specify the optimized conditions for non thermal recovery and its comparison with steam injection

- Performing the experimental studies in fire pipe in order to provide primary data for those heavy oil reservoirs with appropriate parameters in using combustion in situ

\section{Acknowledgement}

I would like to express my special thanks of gratitude to my teacher Prof. Maria João Pereira as well as our principal Prof. Amílcar Soares who gave me the golden opportunity to do this wonderful project, which also helped me in doing a lot of Research and i came to know about so many new things I am really thankful to them. Secondly i would also like to thank my parents and friends who helped me a lot in finalizing this project within the limited time frame.

\section{Ethics}

This article is original and contains unpublished material. The corresponding author confirms that all of the other authors have read and approved the manuscript and that there are no ethical issues.

\section{References}

Abbasi, M., A. Sanati and M. Allahyari, 2015. Simulation study for production of heavy oil: A case study of soroosh oil field, Southern Iran. Int. J. Chem. Petro. Sci.
Butler, R.M. and G.S. Mcnab, 1981. Theoretical studies on the gravity drainage of heavy oil during in-situ steam heating. Canad. J. Chem. Eng., 59: 455-460. DOI: $10.1002 /$ cjce. 5450590407

Butler, R.M. and I.J. Mokrys, 1991. A new process (VAPEX) for recovering heavy oils using hot water and hydrocarbon vapour. J. Canadian Petroleum Technol., 30: 1-11. DOI: 10.2118/91-01-09

Butler, R.M., 1991. Thermal Recovery of Oil and Bitumen. 1st Edn., Prentice Hall, Englewood Cliffs, N.J., ISBN-10: 0139149538, pp: 528.

Gates, I.D. and N. Chakrabarty, 2006. Optimization of Steam-Assisted Gravity Drainage (SAGD) in ideal mcmurray reservoir. J. Canad. Petro. Technol., 45: 54-62. DOI: 10.2118/06-09-05

Moshtaghian, A., R. Malekzadeh and A. Azarpanah, 1988. Heavy Oil Discovery in Iran. Proceedings of the 4th UNITAR/UNDP International Conference on Heavy Crude and Tar Sands, (CTS 88), Edmonton, AB, Canada, pp: 235-243.

Nasr, T.N. and O.R. Ayodele, 2006. New hybrid steamsolvent processes for the recovery of heavy oil and bitumen. Proceedings of the International Petroleum Exhibition and Conference, Nov. 5-8, Abu Dhabi. DOI: $10.2118 / 101717-\mathrm{MS}$

Shafiei, A., M.B. Dusseault, H. Memarian and B. Samimi Sadeh, 2007. Production technology selection for Iranian naturally fractured heavy oil reservoirs. Proceedings of the 8th Canadian International Petroleum Conference, Jun. 12-14, Petroleum Society of Canada, Canada, pp: 1-16. DOI: 10.2118/2007-145

Souraki, Y., M. Ashrafi, H. Karimaie and O. Torsaeter, 2012. Experimental analyses of Athabasca bitumen properties and field scale numerical simulation study of effective parameters on SAGD performance. Energy Environ. Res. DOI: 10.5539/eer.v2n1p140

Souraki, Y., M. Ashrafi, H. Karimaie and O. Torsaeter, 2013. A comparative field-scale simulation study on feasibility of SAGD and ES-SAGD processes in naturally fractured bitumen reservoirs. Energy Environ. Res. DOI: 10.5539/eer.v3n1p49

USGS, 2007. Heavy oil and natural bitumen resources in geological basins of the world. U.S. Geological Survey. 